\title{
Trump administration shutters clinical guidelines database
}

n Cite as: CMAJ 2018 July 9;190:E841. doi: 10.1503/cmaj.109-5624

Posted on cmajnews.com on June 19, 2018.

$\mathbf{T}$ he United States government has defunded the Agency for Healthcare Research and Quality (AHRQ)'s national guidelines clearinghouse, a onestop shop for clinicians and policy makers to access the latest evidence-based recommendations on care.

The online database will shut down on July 16 . It houses and summarizes more than 4000 clinical practice guidelines and draws an average 200,000 visitors each month. Although this information will continue to exist scattered across the
Internet and other sources, it will now be harder to track down. Clinical practice guidelines are often controversial and the AHRQ has been unpopular with some clinicians whose autonomy and earnings were threatened by its recommendations.

"Killing these resources to save a few hundred thousand dollars per year is a penny-wise, pound-foolish decision, and your health and mine will be poorer for it," said Dr. Kenneth Lin, a family physician on the faculty of Georgetown University's medical school.

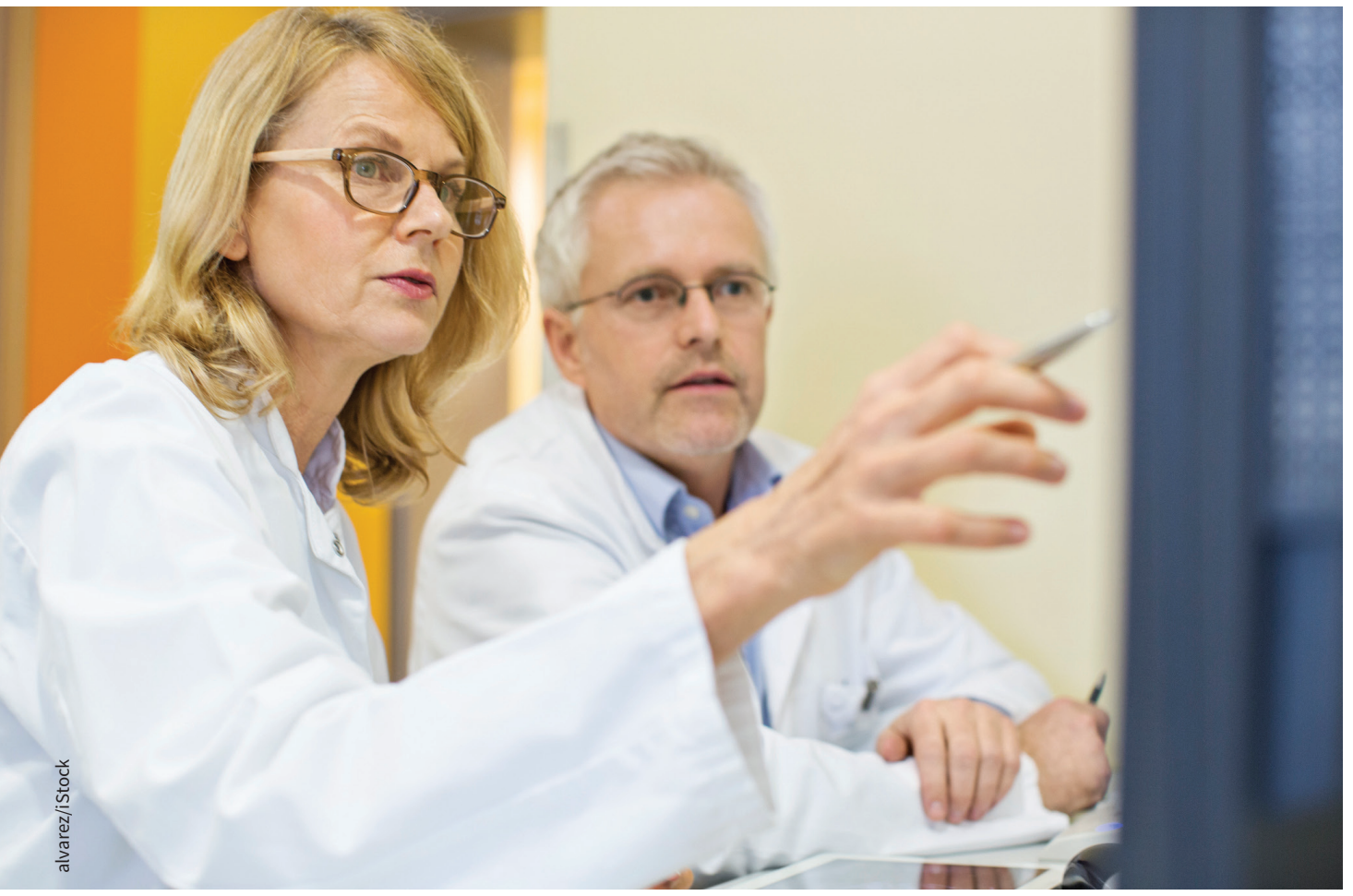

Clinicians and health policy-makers will soon lose a key source of evidence-based advice.
Lin claimed that the AHRQ's work is more necessary than ever as the number of conflicting and questionable guidelines increases. "This is research and evidence that no one, healthy or ill, can afford to lose."

The elimination of the clearinghouse comes after nearly a decade of cuts to the AHRQ, which supports research into making health care safer, less wasteful and more effective. Adjusting for inflation, AHRQ's annual budget is $\$ 120$ million short of its 2010 level. President Donald Trump's administration is also proposing to dissolve the agency into the National Institutes of Health (NIH) with a $21 \%$ budget cut from 2017.

"The coupling of a potential reorganization of AHRQ within the NIH with a proposal for a major budget cut to the $\mathrm{NIH}$ should raise significant warning flags for the health services and primary care research communities," according to Dr. Andrew Bindman, former AHRQ director.

According to the ARHQ, it's possible another organization will take over managing the guidelines clearinghouse. However, "it is not clear" when or if the clearinghouse or something like it will be online again.

Lauren Vogel, CMAJ 